\title{
Supply Chain Coordination Contracts under Double Sided Disruptions Simultaneously
}

\author{
Huan Zhang, ${ }^{1}$ Yang Liu, ${ }^{1}$ and Jingsi Huang ${ }^{2}$ \\ ${ }^{1}$ Department of Economic Management, North China Electrical Power University, Baoding 071000, China \\ ${ }^{2}$ Department of Industrial Engineering \& Management, College of Engineering, Peking University, Haidian District, \\ Beijing 100871, China \\ Correspondence should be addressed to Huan Zhang; hd0086@126.com
}

Received 3 June 2015; Revised 18 July 2015; Accepted 27 July 2015

Academic Editor: Young Hae Lee

Copyright (c) 2015 Huan Zhang et al. This is an open access article distributed under the Creative Commons Attribution License, which permits unrestricted use, distribution, and reproduction in any medium, provided the original work is properly cited.

\begin{abstract}
Supply chain coordination models are developed in a two-echelon supply chain with double sided disruptions. In a supply chain system, the supplier may suffer from the product cost disruption and the retailer suffers from the demand disruption simultaneously. The purpose of this study is to design proper supply chain contracts, under which the supply chain with double sided disruption can be coordinated. Firstly, the centralized decision-making models are applied to find the optimal price and quantity under three cases as the baseline. The different cases are divided by the different relationship between the product cost disruption and the demand disruption. Secondly, two different types of contracts are introduced to coordinate the whole supply chain. One is all-unit wholesale quantity discount policy (AQDP) contract, and the other one is capacitated linear pricing policy (CLPP) contract. And it is found out that the gap between the demand disruption and the product cost disruption is the key factor to influence the supply chain coordination. Some numerical examples and sensitivity analysis are given to illustrate the models. The AQDP contracts are listed out under different cases to show how to use it under double sided disruptions.
\end{abstract}

\section{Introduction}

Supply chain risk management is becoming an increasingly important area. In the past several years, there has been a shift of focus from creating efficient supply chains to reliable and efficient supply chains. This shift is due to the large-scale negative impacts of supply chain disruptions in global supply chain networks. For example, an earthquake in Taiwan in 1999 damaged the manufacturing facilities of several major semiconductor suppliers and disrupted the flow of components to many PC and laptop manufacturers [1]. During the Chinese Winter storm in early 2010, many power plants in southeastern China contacted coal traders to seek imported coals from foreign countries, as the on-hand coal stocks at many of them were below the critical level [2].

Either the supplier's or the retailer's disruptions could not only cut down the efficiency of the whole supply chain but also exert an influence on the supply chain contract [3-5]. Either the supplier or the retailer suffers from disruptions due to economic policies adjustment, transportation delays, or natural disasters. We should be obliged to take the disruption management into consideration. On the one hand, the supplier may experience disruptions, such as [6-10]. On the other hand, the retailer may go through the unexpected changes of market demands, taking, for example, [11-14]. However, the total supply chain may be influenced by the emergency at the same time. Therefore, it is of great significance and urgency to conduct the research on supply chain contracts under double sided disruptions simultaneously. Some researchers have paid some attention to the models including both the supply disruption and the demand disruption, which aimed at the optimal inventory policies [15-17]. The supply disruptions mostly affect the manufacture cost, so normally the supply disruption can be seen as the product cost disruption in [1821]. So we consider the supplier experiences the product cost disruption. But in this paper, we mean to contribute from the supply chain coordination contract aspect for analysis of the supply chain with double sided disruptions. Specifically, our main contributions are twofold as follows. The first one is, according to the different relationship between the 
cost disruption and the demand disruption, the centralized decision-making models are divided into three cases. And the optimal price and quantity under three cases are listed out as the baseline. Secondly, two different types of contracts are introduced in order to coordinate the supply chain with cost disruption and demand disruption simultaneously. One is all-unit wholesale quantity discount policy (AQDP) contract, and the other one is capacitated linear pricing policy (CLPP) contract. And it is found out that the gap between the demand disruption and the product cost disruption is the key factor to influence the supply chain coordination.

The rest of this paper is as follows: In Section 2, we review the related literature. Section 3 outlines our basic model under no disruption. In Section 4, we analyze how to develop a scheme facing with double sided disruptions under centralized decision-making. Section 5 shows how the all-unit wholesale quantity discount policy (AQDP) contract and capacitated linear pricing policy (CLPP) contract could coordinate the supply chain when both sides make their own independent decision. In Section 6, we give some numerical examples to elaborate the above theorems. Section 7 will draw the conclusions and future research.

\section{Related Literature}

Since we study how the supply chain can be coordinated while suffering from double sided disruptions simultaneously, our research is built upon the disruption management literature. Broadly speaking, the impact of disruption management is studied in the supply chain contract framework. On the one hand, demand disruption is a kind of disruption management in supply chains that has been extensively studied in the literature. For instance, Qi et al. [22] design various coordination contract when demand disruption influences the entire supply chain. Xiao et al. [23] examine the coordination scheme when there are several competitive retailers in the supply chain which is suffering from the demand disruption. Cachon and Lariviere [24] develop the allocation reactive plan with the limited capacity of supplier while the retailers meet with the market demand changes. On the other hand, suppliers' cost disruption is another kind of important disruption management in supply chains and has also received substantial attention (Wang et al. [25]; Parlar and Perry [26]; Parlar and Berkin [27]; Heimann and Waage [28]). Corbett et al. [29] present how contracts should be designed by a retailer when a supplier suffers from cost disruption. They establish a general framework to develop the dilemma of supply chains. Sarkar et al. [6] discuss pricing competition between multiple suppliers, all of whom have a disruption risk. They focus on a single uncertain demand and model the retailer's products based on the number of suppliers they choose to order from.

Our paper is distinguished from all the aforementioned papers because both sides of the supply chain with their own disruption result in that existing no main principal, whereas all the above papers investigate a unilateral disruption management. There have been some recent papers on the double sided asymmetric information in very different contexts; see, for example, Yao et al. [30], Zhang and Luo [31], Wang et al. [32], and Wang et al. [33]. However, our research cast new light on how to design different styles of supply chain contracts under double sided disruptions simultaneously; this point has no count part in all the sequential screening papers.

Supply chain coordination with contracts is the most closely related research to our work. Cachon [34] introduces six different kinds of contract to coordinate supply chains. Particularly, our paper is related to the vast literature on the wholesale quantity discount contract. Cachon [34] explains the difference between the all-unit and incremental quantity discount contract. Based on that, some papers focus on the discount contract, such as [35-37]. Giri et al. [38] launched researches on a multi-manufacturer-one-retailer model to develop the ordering plan with the discount contract. Therefore, both sides could achieve the maximum joint profit.

\section{Baseline Case}

Consider a supply chain with one supplier and one retailer [33]. The retailer purchases a kind of product from the supplier and then sells it in the market. The notations that will be used throughout this paper are given below:

$D$ is the retailer's demand,

$M$ is the maximum market scale,

$k$ is a coefficient of price sensitivity,

$\pi^{S}$ is the profit of supplier,

$\pi^{R}$ is the profit of retailer,

$\pi^{\mathrm{SC}}$ is the profit of the total supply chain,

$p$ is the retail price,

$c$ is the supplier's unit production cost,

$Q$ is the order quantity,

$w$ is the unit wholesale price,

$\beta_{1}$ is the marginal costs associated with the incremental increase in demand,

$\beta_{2}$ is the marginal costs associated with the incremental decrease in demand,

$\Delta M$ is the demand disruption,

$\Delta c$ is the cost disruption.

For the illustrative purpose, we use an exponential function of the price $p$ as follows to describe the retailer's demand during a supply cycle: $D=M * \exp (-k p)$ [39]. Let $\pi^{S}, \pi^{R}$ denote the profit of supplier and retailer, respectively. The profit of the supply chain is $\pi^{\mathrm{SC}}=\pi^{S}+\pi^{R}$, supposing that $\pi^{S}=\alpha \pi^{\mathrm{SC}}$, where $0<\alpha<1$.

Suppose that the supplier's unit quantity cost is $c$; thus given the retail price $p$, the supply chain profit is $\pi^{\mathrm{SC}}\left(p^{*}\right)=$ $M * \exp (-k p) *(p-c)$. Using simply algebra, we know that when $p^{*}=1 / k+c$. Substituting this value into the former expression, we can get $\pi_{\max }^{\mathrm{SC}}\left(p^{*}\right)=(M / k) * \exp (-1-k c)$. Consequently, the retailer's optimal order quantity equals the supplier's original quantity plan, as $Q^{*}=M * \exp (-1-k c)=$ $\exp (\operatorname{In} M-1-k c)$. In the rest of this paper, $\Delta M$ and $\Delta c$ denote 
the demand and cost disruption, respectively. We assume that when supply disruption occurs, the maximum market scale faced by the retail shifts from $M$ to $M+\Delta M$.

There is one problem in achieving the maximum supply chain profit $\pi_{\max }^{\mathrm{SC}}\left(p^{*}\right)$, that is, how to share the profit between the two parties. One of the most common approaches is to design appropriate contracts for the supplier. This paper applies two different types. The first one is the wholesale quantity discount policy. Particularly, we study the all-unit wholesale quantity discount policy, denoted by $\operatorname{AQDP}\left(w_{1}, w_{2}, q_{0}\right)$ with $w_{1}>w_{2}$. If the retailer orders $Q<q_{0}$, the unit price is $w_{1}$. Otherwise, the unit price becomes $w_{2}$. And the latter one is a capacitated linear pricing policy $\operatorname{CLPP}(w, C)$. The unit wholesale price is $w$, whereas the retailer is limited to sending for less than the arranging quantity $C$.

\section{Centralized Decision-Making}

In the disruption model, we assume that there is a central decision-maker who seeks maximizing the total profit. During the disruption captured by the demand disruption $\Delta M$ and the cost disruption $\Delta c$, the realized price is found to be $p=(\operatorname{In} M+\Delta M-\operatorname{In} Q) / k$ and the supply chain profit can be written as

$$
\begin{aligned}
f(Q)= & Q\left(\frac{\operatorname{In} M+\Delta M-\operatorname{In} Q}{k}-c-\Delta c\right) \\
& -\beta_{1}\left(Q-Q^{*}\right)^{+}-\beta_{2}\left(Q^{*}-Q\right)^{+},
\end{aligned}
$$

where the parameters $\beta_{1}>0$ and $\beta_{2}>0$ are the marginal costs associated with the incremental increase or decrease in demand, respectively, and $(x)^{+}=\max \{x, 0\}$.

Lemma 1. Suppose $Q^{\prime}$ maximizes $f(Q)$ in (1). Then $Q^{\prime}>Q^{*}$ if $\Delta M>k \Delta c$; otherwise $Q^{\prime}<Q^{*}$.

Lemma 1 demonstrates that the order quantity will increase with the enlargement of the market scale. From Lemma 1 , when $\Delta M>k \Delta c$, the problem of maximizing $f(Q)$ reduces to

$$
\begin{aligned}
f_{1}(Q)= & Q\left(\frac{\operatorname{In} M+\Delta M-\operatorname{In} Q}{k}-c-\Delta c\right) \\
& -\beta_{1}\left(Q-Q^{*}\right) .
\end{aligned}
$$

Using the first-order condition $f_{1}^{\prime}(Q)=0$ and solving for $Q$ give

$$
Q_{1}=\exp \left[(\operatorname{In} M-1-k c)+\Delta M-k\left(\Delta c+\beta_{1}\right)\right] .
$$

We analyze $Q_{1}$ regarding the constraint $Q>Q^{*}$. There exist two cases.

Case 1. $\Delta M>k\left(\Delta c+\beta_{1}\right)$; then $Q>Q^{*}$, showing that $f_{1}(Q)$ is maximized at $Q_{1}$. Therefore, let $Q_{\text {casel }}^{\prime}=Q_{1}$.

Case 2. $k \Delta c<\Delta M<k\left(\Delta c+\beta_{1}\right)$; then $Q<Q^{*}$; thus $f_{1}(Q)$ is maximized at $Q^{*}$. Let $Q_{\text {case } 2}^{\prime}=Q^{*}$.

In summary, we know that the quantity will increase if the demand disruption $\Delta M$ is larger than $k\left(\Delta c+\beta_{1}\right)$.
Consequently, the quantity plan is dependent on the gap between the demand disruption and the cost disruption. We continue to analyze the corresponding price now.

Nevertheless, the optimal price $p^{\prime}$ will increase when the market scale increases. Substituting $Q_{\text {case1 }}^{\prime}$ and $Q_{\text {case2 }}^{\prime}$ into the former given expression $p=(\operatorname{In} M+\Delta M-\operatorname{In} Q) / k$, we can obtain

$$
\begin{aligned}
p_{\text {case } 1}^{\prime} & =\frac{\operatorname{In} M+\Delta M-\operatorname{In} Q_{\text {case } 1}^{\prime}}{k}=\frac{1}{k}+c+\Delta c+\beta_{1} \\
& =p^{*}+\left(\Delta c+\beta_{1}\right), \\
p_{\text {case } 2}^{\prime} & =\frac{\operatorname{In} M+\Delta M-\operatorname{In} Q_{\text {case } 2}^{\prime}}{k}=\frac{1}{k}+c+\frac{\Delta M}{k} \\
& =p^{*}+\frac{\Delta M}{k} .
\end{aligned}
$$

Now we can solve the maximum supply chain profit at this price and quantity:

$$
\begin{aligned}
\pi_{\text {case } 1}^{\mathrm{SC}}= & Q_{\text {case } 1}^{\prime} *\left(p_{\text {case } 1}^{\prime}-c\right) \\
= & \exp \left[\Delta M-k\left(\Delta c+\beta_{1}\right)\right] \\
& *\left(\pi_{\text {max }}^{\mathrm{SC}}+\left(\Delta c+\beta_{1}\right) Q^{*}\right) \\
= & f_{\Delta} *\left(\pi_{\text {max }}^{\mathrm{SC}}+\left(\Delta c+\beta_{1}\right) Q^{*}\right), \\
\pi_{\text {case } 2}^{\mathrm{SC}} & Q_{\text {case }}^{\prime} *\left(p_{\text {case } 2}^{\prime}-c\right)=\pi_{\text {max }}^{\mathrm{SC}}+\Delta M \frac{Q^{*}}{k} .
\end{aligned}
$$

We use the function $f_{\Delta}=\exp \left[\Delta M-k\left(\Delta c+\beta_{1}\right)\right]$ to denote the maximum profit for the new cost and new market scale. We think out the other case where $\Delta M<k \Delta c$.

The problem of maximizing $f(Q)$ reduces to (6)

$$
\begin{aligned}
f_{1}(Q)= & Q\left(\frac{\operatorname{In} M+\Delta M-\operatorname{In} Q}{k}-c-\Delta c\right) \\
& -\beta_{2}\left(Q^{*}-Q\right) .
\end{aligned}
$$

Likewise, we can divide $\Delta M<k \Delta c$ into case $3\left(k\left(\Delta c-\beta_{2}\right)<\right.$ $\Delta M<k \Delta c)$ and case $4\left(\Delta M<k\left(\Delta c-\beta_{2}\right)\right)$. Leaving out the details, we can obtain

$$
\begin{aligned}
& Q^{\prime}=\left\{\begin{array}{l}
Q_{\text {case3 }}^{\prime}=Q^{*} \\
Q_{\text {case4 }}^{\prime}=\exp \left[(\operatorname{In} M-1-k c)+\Delta M-k\left(\Delta c-\beta_{2}\right)\right]
\end{array}\right. \\
& p^{\prime}=\left\{\begin{array}{l}
p_{\text {case3 }}^{\prime}=p^{*}+\frac{\Delta M}{k} \\
p_{\text {case }}^{\prime}=p^{*}+\left(\Delta c-\beta_{2}\right)
\end{array}\right. \\
& \pi^{\mathrm{SC}} \\
& =\left\{\begin{array}{l}
\pi_{\text {case3 }}^{\mathrm{SC}}=\pi_{\text {max }}^{\mathrm{SC}}+\Delta M \frac{Q^{*}}{k} \\
\pi_{\text {case4 }}^{\mathrm{SC}}=\exp \left[\Delta M-k\left(\Delta c-\beta_{2}\right)\right] *\left(\pi_{\text {max }}^{\mathrm{sC}}+\left(\Delta c-\beta_{2}\right) Q^{*}\right) .
\end{array}\right.
\end{aligned}
$$

Summarizing the above works, we have the following.

Theorem 2. Given double sided disruptions in both market scale $\Delta M$ and producing cost $\Delta c$, the supply chain profit is maximized for the following values of the price $p$ and the quantity $\mathrm{Q}$ : 


$$
\begin{aligned}
& Q^{\prime}= \begin{cases}Q^{*} * \exp \left[\Delta M-k\left(\Delta c-\beta_{2}\right)\right] & \text { if } \Delta M<k\left(\Delta c-\beta_{2}\right) \\
Q^{*} & \text { if } k\left(\Delta c-\beta_{2}\right)<\Delta M<k\left(\Delta c+\beta_{1}\right) \\
Q^{*} * \exp \left[\Delta M-k\left(\Delta c+\beta_{1}\right)\right] & \text { if } k\left(\Delta c+\beta_{1}\right)<\Delta M\end{cases} \\
& p^{\prime}= \begin{cases}p^{*}+\left(\Delta c-\beta_{2}\right) & \text { if } \Delta M<k\left(\Delta c-\beta_{2}\right) \\
p^{*}+\frac{\Delta M}{k} & \text { if } k\left(\Delta c-\beta_{2}\right)<\Delta M<k\left(\Delta c+\beta_{1}\right) \\
p^{*}+\left(\Delta c+\beta_{1}\right) & \text { if } k\left(\Delta c+\beta_{1}\right)<\Delta M .\end{cases}
\end{aligned}
$$

Theorem 2 demonstrates that the initial quantity $Q^{*}$ has some robustness under double sided disrupted market scale and producing cost simultaneously. We find out that case 2 and case 3 can be incorporated to only one case due to the same consequence though they belong to different intervines. Hence, latter part of our paper will substitute case 2 into former case 2 and case 3. Moreover, we have to use case 4 instead of former case 3 . There are not changes when the gap between disrupted market scale and producing cost is not so large, such as $k\left(\Delta c-\beta_{2}\right)<\Delta M<k\left(\Delta c+\beta_{1}\right)$. In this condition, adjusting the price could retrieve any disruption expense, while the adjustment equals $\Delta M / k$ which is just related to the demand disruption. Only when either the demand disruption far exceeds the cost disruption $\left(\Delta M>k\left(\Delta c+\beta_{1}\right)\right)$ or the other case $\left(\Delta c>\Delta M / k+\beta_{2}\right)$, will it be essential to change both the price and the quantity.

Figure 1 is used to show the optimal quantity area during centralized decision-making under different cases.

\section{Decentralized Decision-Making}

When the supplier and the retailer make decision all alone under double sided disruption, it is necessary to recoordinate the contract to maximize the total supply chain profit. Hence, we can utilize a modified all-unit wholesale quantity discount contract to realize the maximal profit.

5.1. Case 1: $\Delta M>k\left(\Delta c+\beta_{1}\right)$. In this case, suppose that the supplier wishes to achieve a profit of

$$
\begin{aligned}
\pi_{S}= & \theta \pi_{\text {casel }}^{\mathrm{SC}} \\
= & \theta \exp \left[\Delta M-k\left(\Delta c+\beta_{1}\right)+\operatorname{In} M-1-k c\right] \\
& *\left(\frac{1}{k}+\Delta c+\beta_{1}\right) .
\end{aligned}
$$

Theorem 3. For the case where $\Delta M>k\left(\Delta c+\beta_{1}\right)$ and $\pi_{S}$ defined in (9), the supply chain can be coordinated by $A Q D P\left(w_{1}, w_{2}, Q_{\text {case } 1}^{\prime}\right)$ where

$$
\begin{aligned}
& w_{1}>c+\Delta c+\beta_{1}-\frac{\operatorname{In}(1-\theta)}{k}-\frac{\operatorname{In}\left(1+k \Delta c+k \beta_{1}\right)}{k} \\
& w_{2}=c+\theta\left(\frac{1}{k}+\Delta c+\beta_{1}\right) .
\end{aligned}
$$

Proof. The retailer's profit is $\pi_{R}=Q_{\text {casel }}^{\prime}\left(p_{1}^{\prime}-w_{2}\right)=(1-$ $\theta) \pi_{\text {case } 1}^{\text {SC }}$

$$
\begin{aligned}
\exp & {\left[\Delta M-k\left(\Delta c+\beta_{1}\right)+\operatorname{In} M-1-k c\right] } \\
& *\left(\frac{1}{k}+c+\Delta c+\beta_{1}-w_{2}\right) \\
= & (1-\theta) \exp \left[\Delta M-k\left(\Delta c+\beta_{1}\right)+\operatorname{In} M-1-k c\right] \\
& *\left(\frac{1}{k}+\Delta c+\beta_{1}\right)
\end{aligned}
$$

so $w_{2}=c+\theta\left(1 / k+\Delta c+\beta_{1}\right)$.

If the retailer's ordering quantity $Q_{2}$ is no more than $Q_{\text {casel }}^{\prime}$ and she takes the price $p_{1}^{\prime}$, her profit

$$
\pi_{R}\left(Q_{2}\right)<\pi_{R}\left(Q_{\text {case } 1}^{\prime}\right) .
$$

So $\pi_{R}\left(Q_{2}\right)=Q_{2} *\left(\left(\operatorname{In} M+\Delta M-\operatorname{In} Q_{2}\right) / k-w_{1}\right)$ is maximized where $Q_{2}=\exp \left(\operatorname{In} M+\Delta M-k w_{1}-1\right)$.

Substitute the value of $Q_{2}$ into (12), we obtain

$$
\begin{aligned}
& \frac{\exp \left(\operatorname{In} M+\Delta M-k w_{1}-1\right)}{k} \\
& <\exp \left[\Delta M-k\left(\Delta c+\beta_{1}\right)+\operatorname{In} M-1-k c\right] \\
& \quad *\left(\frac{1}{k}+c+\Delta c+\beta_{1}-w_{2}\right) .
\end{aligned}
$$

So $w_{1}>c+\Delta c+\beta_{1}-\operatorname{In}(1-\theta) / k-\operatorname{In}\left(1+k \Delta c+k \beta_{1}\right) / k$.

From Theorem 3, we can find out that $\operatorname{AQDP}\left(w_{1}\right.$, $\left.w_{2}, Q_{\text {case1 }}^{\prime}\right)$ is just related with $\Delta c$ where $\Delta M$ far exceeds $\Delta c$, whereas the threshold $Q_{\text {casel }}^{\prime}$ is dependent on both $\Delta M$ and $\Delta c$.

5.2. Case 2: $k\left(\Delta c-\beta_{2}\right)<\Delta M<k\left(\Delta c+\beta_{1}\right)$. For this case, we firstly recall that $\pi_{\text {case2 }}^{\mathrm{SC}}$ can be expressed as

$$
\begin{aligned}
\pi_{\text {case } 2}^{\mathrm{SC}} & =\pi_{\max }^{\mathrm{SC}}+\Delta M \frac{Q^{*}}{k} \\
& =\frac{\exp (\operatorname{In} M-1-k c)}{k}+\Delta M \frac{Q^{*}}{k} .
\end{aligned}
$$

We take this case where $\pi_{S} \geq \exp (\operatorname{In} M-1-k c) / k$. Then we can rewrite supplier's profit as

$$
\pi_{S}=\frac{\exp (\operatorname{In} M-1-k c)}{k}+\theta * \Delta M \frac{Q^{*}}{k},
$$

where $0 \leq \theta<1$ is a parameter specified by the supplier. 


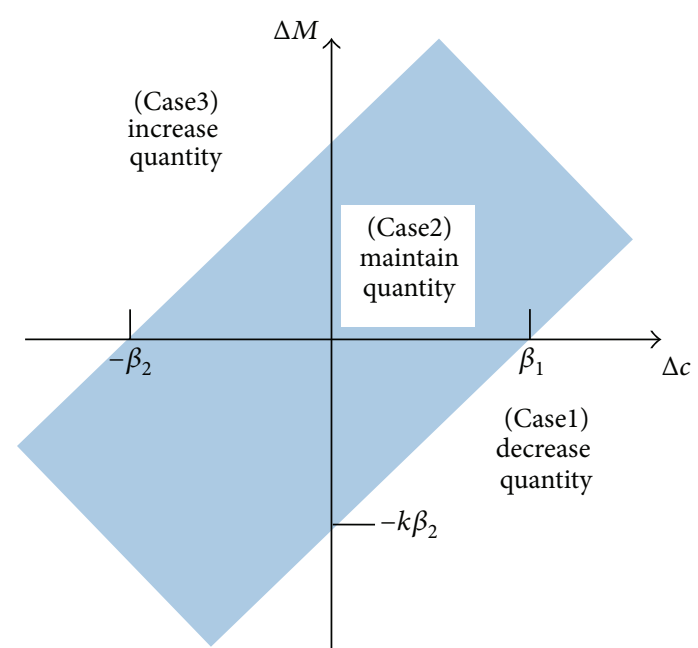

FIGURE 1: Optimal quantity during centralized decision-making.

Theorem 4. When $k\left(\Delta c-\beta_{2}\right)<\Delta M<k\left(\Delta c+\beta_{1}\right)$ and $\pi_{S} \geq$ $\exp (\operatorname{In} M-1-k c) / k$, the supply chain can be coordinated by the $A Q D P\left(w_{1}, w_{2}, Q_{\text {case } 2}^{\prime}\right)$ where

$$
\begin{aligned}
& w_{1}>c+\frac{\Delta M}{k}-\frac{\operatorname{In}(1-\theta)}{k}-\frac{\operatorname{In} \Delta M}{k} \\
& w_{2}=c+\frac{1}{k}+\theta * \frac{\Delta M}{k} .
\end{aligned}
$$

And $\theta$ is defined in (15).

Proof. The retailer's profit is $\pi_{R}=Q_{\text {case } 2}^{\prime}\left(p_{2}^{\prime}-w_{2}\right)=\pi_{\text {case } 2}^{\mathrm{SC}}-\pi_{S}$. So

$$
Q^{*}\left(p_{2}^{\prime}-w_{2}\right)=(1-\theta) * Q^{*} *\left(\frac{\Delta M}{k}\right) ;
$$

then solving for $w_{2}$ gives $w_{2}=c+1 / k+\theta * \Delta M / k$.

Similarly, when the retailer orders $Q_{2}$ that is no more than $Q_{\text {casel }}^{\prime}$, her profit

$$
\pi_{R}\left(Q_{2}\right)<\pi_{R}\left(Q_{\text {case } 2}^{\prime}\right) .
$$

We have previously known that $Q_{2}=\exp \left(\operatorname{In} M+\Delta M-k w_{1}-\right.$ 1).

So $\exp \left(\operatorname{In} M+\Delta M-k w_{1}-1\right) / k<(1-\theta) * Q^{*} *(\Delta M / k)$.

Hence, $w_{1}>c+\Delta M / k-\operatorname{In}(1-\theta) / k-\operatorname{In} \Delta M / k$.

From Theorem 4 , we realize only $\Delta M$ not $\Delta c$ have effects on the all-unit wholesale quantity discount policy where the gap between disrupted market scale and producing cost is not so large. Moreover, $\operatorname{AQDP}\left(w_{1}, w_{2}, Q_{\text {case2 }}^{\prime}\right)$ is not related with the marginal costs $\beta_{1}$ or $\beta_{2}$.

We now consider the case where $\pi_{S}<\exp (\operatorname{In} M-1-k c) / k$ by letting $\pi_{S}=\theta \exp (\operatorname{In} M-1-k c) / k$.

Then $\pi_{T}=Q\left(p-w_{2}\right)=(1-\theta) \exp (\operatorname{In} M-1-k c) / k+\Delta M / k$.

So $w_{2}=c+\theta / k+\Delta M / k-(\Delta M / k) \exp (-\operatorname{In} M+1+k c)$.

Substitute the value of $w_{2}$ into $Q_{2}=\exp (\operatorname{In} M+\Delta M-$ $\left.k w_{1}-1\right)$, we get

$$
\begin{aligned}
Q_{2} & =\exp [(\operatorname{In} M-1-c k) \\
& +(\Delta M \exp (-\operatorname{In} M+1+k c)-\theta)] .
\end{aligned}
$$

When $\exp (\operatorname{In} M-1-k c)<\Delta M / \theta$, it can be shown that $Q_{2}>Q_{\text {case2 }}^{\prime}$ which the retailer will not order $Q_{\text {case2 }}^{\prime}$. Hence, the supply chain cannot be coordinated. We have to introduce the $\operatorname{CLPP}(w, C)$.

Theorem 5. For the case where $k\left(\Delta c-\beta_{2}\right)<\Delta M<k\left(\Delta c+\beta_{1}\right)$ and $\Delta M>\theta * \exp (\operatorname{In} M-1-k c)$, the $\operatorname{CLPP}\left(w, Q_{\text {case } 2}^{\prime}\right)$ could coordinate the supply chain, where

$$
w=c+\frac{\theta}{k}+\frac{\Delta M}{k}-\left(\frac{\Delta M}{k}\right) \exp (-\operatorname{In} M+k c) .
$$

5.3. Case 3: $\Delta M<k\left(\Delta c-\beta_{2}\right)$. For this case, the cost disruption far exceeds the demand disruption. Suppose that the supplier now hopes to realize the following profit:

$$
\begin{aligned}
\pi_{S}= & \theta \pi_{\text {case } 3}^{\mathrm{SC}} \\
= & \theta \exp \left[\Delta M-k\left(\Delta c-\beta_{2}\right)+\operatorname{In} M-1-k c\right] \\
& *\left(\frac{1}{k}+\Delta c-\beta_{2}\right) .
\end{aligned}
$$

Theorem 6. For the case where $\Delta M<k\left(\Delta c-\beta_{2}\right)$ and $\pi_{S}$ defined in (21), the supply chain can be coordinated by $A Q D P\left(w_{1}, w_{2}, Q_{\text {case } 3}^{\prime}\right)$ where

$$
\begin{aligned}
& w_{1}>c+\Delta c-\beta_{2}-\frac{\operatorname{In}(1-\theta)}{k}-\frac{\operatorname{In}\left(1+k \Delta c-k \beta_{2}\right)}{k} \\
& w_{2}=c+\theta\left(\frac{1}{k}+\Delta c-\beta_{2}\right) .
\end{aligned}
$$

Proof. The retailer's profit is $\pi_{R}=Q_{\text {case } 3}^{\prime}\left(p_{3}^{\prime}-w_{2}\right)=(1-$ $\theta) \pi_{\text {case } 3}^{\mathrm{SC}}$

$$
\begin{aligned}
\exp & {\left[\Delta M-k\left(\Delta c-\beta_{2}\right)+\operatorname{In} M-1-k c\right] } \\
* & \left(\frac{1}{k}+c+\Delta c-\beta_{2}-w_{2}\right) \\
= & (1-\theta) \exp \left[\Delta M-k\left(\Delta c-\beta_{2}\right)+\operatorname{In} M-1-k c\right] \\
& *\left(\frac{1}{k}+\Delta c-\beta_{2}\right)
\end{aligned}
$$

so $w_{2}=c+\theta\left(1 / k+\Delta c-\beta_{2}\right)$.

If the retailer's ordering quantity $Q_{2}$ is no more than $Q_{\text {case3 }}^{\prime}$ and she takes the price $p_{3}^{\prime}$, her profit

$$
\pi_{R}\left(Q_{2}\right)<\pi_{R}\left(Q_{\text {case3 }}^{\prime}\right) .
$$

Substitute $Q_{2}=\exp \left(\operatorname{In} M+\Delta M-k w_{1}-1\right)$ into (24), we obtain

$$
\begin{aligned}
& \frac{\exp \left(\operatorname{In} M+\Delta M-k w_{1}-1\right)}{k} \\
& <\exp \left[\Delta M-k\left(\Delta c+\beta_{1}\right)+\operatorname{In} M-1-k c\right] \\
& \quad *\left(\frac{1}{k}+c+\Delta c+\beta_{1}-w_{2}\right) .
\end{aligned}
$$

So $w_{1}>c+\Delta c-\beta_{2}-\operatorname{In}(1-\theta) / k-\operatorname{In}\left(1+k \Delta c-k \beta_{2}\right) / k$.

Moreover, Theorem 6 is similar to Theorem 3. It is apparent that $\operatorname{AQDP}\left(w_{1}, w_{2}, Q_{\text {case3 }}^{\prime}\right)$ just depends on the cost disruption. 
TABLE 1: Sensitivity analysis for the key parameters.

\begin{tabular}{ccccc}
\hline Parameters & $\begin{array}{c}\text { Changes } \\
\text { (in \%) }\end{array}$ & $\begin{array}{c}\text { Optimal } \\
\text { price }\end{array}$ & $\begin{array}{c}\text { Optimal } \\
\text { quantity }\end{array}$ & $\pi_{\max }^{\mathrm{SC}}$ \\
\hline \multirow{4}{*}{$k$} & -50 & +1 & +8.78 & +31.09 \\
& -25 & +0.33 & +3.84 & +9.64 \\
& +25 & -0.2 & -2.99 & -5.10 \\
& +50 & -0.33 & -5.33 & -8.06 \\
\hline & -50 & -0.5 & +8.78 & +8.78 \\
& -25 & -0.25 & +3.84 & +3.84 \\
& +25 & +0.25 & -2.99 & -2.99 \\
& +50 & +0.5 & -5.33 & -5.33 \\
\hline \multirow{3}{*}{$M$} & -50 & - & -6.77 & -6.77 \\
& -25 & - & -3.38 & -3.38 \\
& +25 & - & +3.38 & +3.38 \\
& +50 & - & +6.77 & +6.77 \\
\hline
\end{tabular}

\section{Numerical Examples}

This section gives some numerical examples to inspect supply chain contracts under double sided demand and cost disruptions simultaneously [22]. We let the unit $\operatorname{cost} c=$ 1 , the market scale $M=100$, and the coefficient of price sensitivity $k=1$; then the retailer's demand function is $D=$ $100 * \exp (-p)$. Hence, the optimal price $p^{*}=2$, the optimal quantity $Q^{*}=100 * \exp (-2)$, and the maximum profit of the total supply chain is $\pi_{\max }^{\mathrm{SC}}=100 * \exp (-2)$.

Sensitivity Analysis. We performed the sensitivity analysis by replacing each key parameter by $-50 \%,-25 \%,+25 \%$, and $+50 \%$ one at a time and keeping remaining parameters unchanged. The effects of changes of the system parameters on the optimal price, the optimal quantity, and the maximum total profit are summarized in Table 1 for our numerical examples.

The percentage change in the optimal price indicates that a parameter such as $k$ is more sensitive than that such as $c$ to the optimal price. From the sensitivity analysis results, we know that, on the one hand, parameter $k$ is more sensitive than those such as $c$ and $M$ to the maximum total profit; on the other hand, increasing the value of some parameters such as $k$ and $c$ results in the increased optimal quantity of the whole system; otherwise it results in the decreased quantity.

Suppose that the demand disruption $\Delta M$ and the cost disruption $\Delta c$ belong to the interval $[-1,1]$. Moreover, the marginal costs associated with the incremental increase or decrease $\beta_{1}=\beta_{2}=0.5$. Thus, we can utilize the surface of the optimal quantity under various cases, just as Figure 2.

From Figure 2, we can learn that $Q^{*}$ has some robustness when the gap between disrupted market scale and producing cost is not so large. Moreover, $Q^{*}$ declines during the dominant cost disruption; in other word, the cost disruption far exceeds the demand disruption. It is also in line with the reality that the quantity should be decreased when upstream cost fluctuates violently. In the same way, $Q^{*}$ increases when the demand disruption dominates.

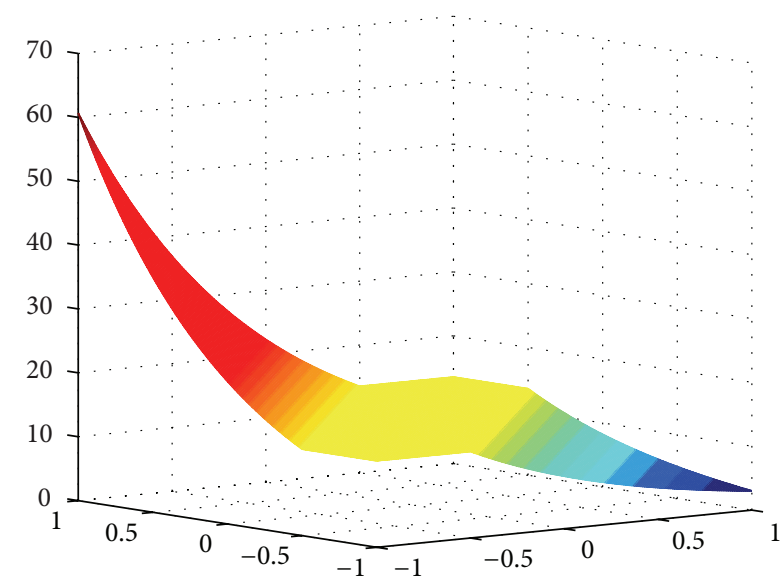

FIgURE 2: The surface of the optimal quantity.

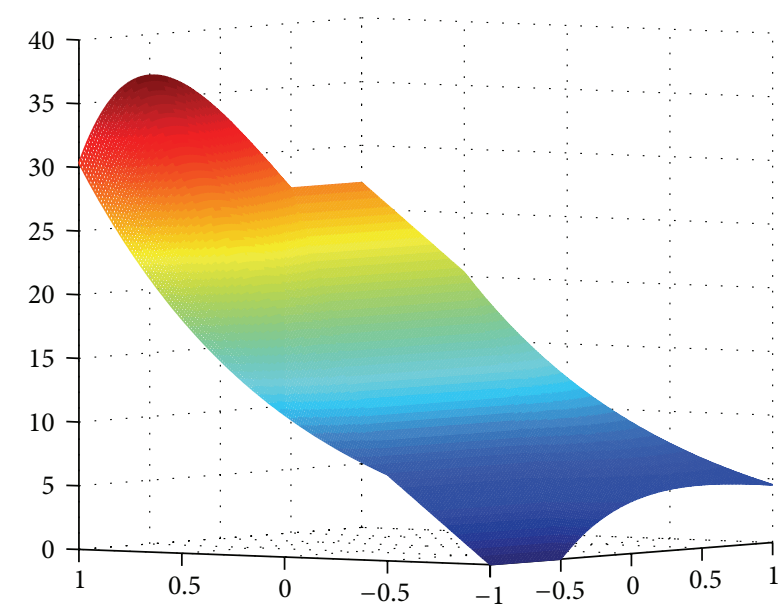

Figure 3: The surface of the supply chain profit.

Then the whole supply chain's profit is considered under different cases (see Figure 3).

Figure 3 tells us the maximum supply chain profit will increase with the raising of both cost disruption and demand disruption. Particularly, the profit may reach at the peak when the demand disruption is dominant over the cost disruption.

Based on the above assumptions and calculations, we could provide some numerical examples to argue how the AQDP contract can coordinate the supply chain under both cost disruption and demand disruption considering from Theorem 3 to Theorem 6 . Specifically, we can obtain which types of cases it belongs to on account of the gap between demand disruption and cost disruption at first. Then by calculating different parameters about $\operatorname{AQDP}\left(w_{1}, w_{2}, q_{0}\right)$, we get Table 2.

From Table 2, we can find out the following.

(1) The types of case are varying with both product cost disruption and demand disruption. Hence, there is not any immutable contract even in such a small section. Moreover, how to design the contract exclusively 
TABLE 2: AQDP $\left(w_{1}, w_{2}, q_{0}\right)$ based on various $\Delta M$ and $\Delta c$.

\begin{tabular}{|c|c|c|c|c|c|c|c|c|}
\hline$\Delta M$ & $\Delta c$ & $\Delta M-\Delta c$ & Types & $\pi_{\max }^{\mathrm{SC}}$ & $w_{1}$ & $w_{2}$ & $q_{0}$ & $\operatorname{AQDP}\left(w_{1}, w_{2}, q_{0}\right)$ \\
\hline-1.00 & -0.40 & -0.60 & Case 3 & 1.22 & 1.10 & 1.07 & 4.50 & $\operatorname{AQDP}(1.10,1.07,4.50)$ \\
\hline-0.90 & -0.50 & -0.40 & Case 2 & 1.35 & 1.10 & 1.05 & 13.53 & $\operatorname{AQDP}(1.10,1.05,13.53)$ \\
\hline-0.80 & -0.60 & -0.20 & Case 2 & 2.71 & 1.20 & 1.10 & 13.53 & $\operatorname{AQDP}(1.20,1.10,13.53)$ \\
\hline-0.70 & -0.70 & 0.00 & Case 2 & 4.06 & 1.30 & 1.15 & 13.53 & $\operatorname{AQDP}(1.30,1.15,13.53)$ \\
\hline-0.60 & -0.80 & 0.20 & Case 2 & 5.41 & 1.40 & 1.20 & 13.53 & $\operatorname{AQDP}(1.40,1.20,13.53)$ \\
\hline-0.50 & -0.90 & 0.40 & Case 2 & 6.77 & 1.50 & 1.25 & 13.53 & $\operatorname{AQDP}(1.50,1.25,13.53)$ \\
\hline-0.40 & -1.00 & 0.60 & Case 1 & 7.48 & 1.50 & 1.33 & 40.66 & $\operatorname{AQDP}(1.50,1.33,40.66)$ \\
\hline-0.30 & 1.00 & -1.30 & Case 3 & 9.12 & 2.50 & 2.00 & 2.24 & $\operatorname{AQDP}(2.50,2.00,2.24)$ \\
\hline-0.20 & 0.90 & -1.10 & Case 3 & 10.40 & 2.40 & 1.93 & 2.73 & $\operatorname{AQDP}(2.40,1.93,2.73)$ \\
\hline-0.10 & 0.80 & -0.90 & Case 3 & 11.79 & 2.30 & 1.87 & 3.34 & $\operatorname{AQDP}(2.30,1.87,3.34)$ \\
\hline 0.10 & 0.70 & -0.60 & Case 3 & 14.69 & 2.20 & 1.80 & 4.50 & $\operatorname{AQDP}(2.20,1.80,4.50)$ \\
\hline 0.20 & 0.60 & -0.40 & Case 2 & 16.24 & 2.20 & 2.13 & 13.53 & $\operatorname{AQDP}(2.20,2.13,13.53)$ \\
\hline 0.30 & 0.50 & -0.20 & Case 2 & 17.59 & 2.30 & 2.20 & 13.53 & $\operatorname{AQDP}(2.30,2.20,13.53)$ \\
\hline 0.40 & 0.40 & 0.00 & Case 2 & 18.95 & 2.40 & 2.27 & 13.53 & $\operatorname{AQDP}(2.40,2.27,13.53)$ \\
\hline 0.50 & 0.30 & 0.20 & Case 2 & 20.30 & 2.50 & 2.33 & 13.53 & $\operatorname{AQDP}(2.50,2.33,13.53)$ \\
\hline 0.60 & 0.20 & 0.40 & Case 2 & 21.65 & 2.60 & 2.40 & 13.53 & $\operatorname{AQDP}(2.60,2.40,13.53)$ \\
\hline 0.70 & 0.10 & 0.60 & Case 1 & 23.93 & 2.60 & 2.07 & 40.66 & $\operatorname{AQDP}(2.60,2.07,40.66)$ \\
\hline 0.80 & -0.10 & 0.90 & Case 1 & 28.27 & 2.40 & 1.93 & 54.88 & $\operatorname{AQDP}(2.40,1.93,54.88)$ \\
\hline 0.90 & -0.20 & 1.10 & Case 1 & 32.06 & 2.30 & 1.87 & 67.03 & $\operatorname{AQDP}(2.30,1.87,67.03)$ \\
\hline 1.00 & -0.30 & 1.30 & Case 1 & 36.14 & 2.20 & 1.80 & 81.87 & $\operatorname{AQDP}(2.20,1.80,81.87)$ \\
\hline
\end{tabular}

depends on the gap between the demand disruption and the cost disruption.

(2) Except Theorem 5 when the supplier is allocated so little, the profit allocation parameter $\theta$ is assigned to $2 / 3$. In other words, the supplier earns two-thirds of total supply chain profits.

(3) Example 1: we take $\Delta M=0.7$ and $\Delta c=0.1$, for example. Thus, we should consider Theorem 3 and this case belongs to case 1 . Calculating it, we get $\operatorname{AQDP}(2.60,2.07,40.66)$. It would be probably best for the retailer to choose the wholesale price 2.07, place an order for 40.66 , and sell them with the price at 2.60 .

Example 2: we take $\Delta M=0.1$ and $\Delta c=0.7$, for example. Thus, we should consider Theorem 6 and this case belongs to case 3. Calculating it, we get $\operatorname{AQDP}(2.20,1.80,4.50)$. It would be probably best for the retailer to choose the wholesale price 1.80 , place an order for 4.50, and sell them with the price at 2.20.

Sensitivity Analysis. The optimal values of the different parameters change significantly with changes $(-50 \%,-25 \%$, $+25 \%,+50 \%)$ in Table 3 . On the basis of the sensitivity analysis of different parameters, the following features are observed: From Table 3, we can conclude that parameter $\beta_{1}$ is the same sensitive to $\beta_{2}$. From the sensitivity analysis results, we obtain that increasing value of all key parameters has no effect on the optimal price of the whole system owing to
TABLE 3: Sensitivity analysis for the key parameters of Examples 1 and 2.

\begin{tabular}{lcccc}
\hline Parameters & Changes (in \%) & Types & $w_{1}$ & $w_{2}$ \\
\hline \multirow{3}{*}{$\beta_{1}$} & -50 & Case 1 & -0.25 & -0.167 \\
& -25 & Case 1 & -0.125 & -0.083 \\
& +25 & Case 2 & - & - \\
& +50 & Case 2 & - & - \\
\hline \multirow{3}{*}{$\beta_{2}$} & -50 & Case 3 & +0.25 & +0.167 \\
& -25 & Case 3 & +0.125 & +0.083 \\
& +25 & Case 2 & - & - \\
\hline
\end{tabular}

that the optimal price has no correlation with the marginal costs associated with the incremental increase or decrease in demand.

\section{Conclusions}

The paper deals with double sided demand and cost disruptions simultaneously. Either the supplier or the retailer suffer from disruptions due to economic policies adjustment, transportation delays, or natural disasters. We should be obliged to take the disruption management into consideration. It is of great significance and urgency to conduct the research on supply chain contracts under double sided disruptions simultaneously. We contribute from the supply chain coordination contract aspect for analysis of the supply chain with double 
sided disruptions. In this paper we obtain the parameters of the all-unit wholesale quantity discount contract under three various types of cases based on centralized decision-making and decentralized decision-making. We can conclude that AQDP and CLPP can coordinate the supply chain which is suffering from both upstream and downstream disruption. Both upstream one and downstream one within the entire supply chain are ought to design different contracts when suffering from cost disruption and demand disruption at the same time. That is to say, it is evident that aforementioned unilateral disruption can be treated as the special case of both sided disruption. For instance, we can regard unilateral upstream cost disruption as both sided one when the cost disruption far exceeds the demand disruption.

The gap between the supplier's product cost disruption and the retailer's demand disruption is the most significant. When the gap is not so large, ordering quantity is immutable and the price varies only with the demand disruption based on the original optimal price, whereas the quantity and the price fluctuate drastically when the gap is too large. No matter which case the supply chain suffers from, the price is dependent on only the product cost disruption. Nevertheless accordingly, the quantity is influenced by both disruption. When the cost disruption far exceeds the demand disruption, the quantity will decrease. Particularly, the more vast the gap is, the faster the quantity decreases. Likewise, similar is the other case.

Although in this paper we are primarily interested in the coordination of the single-period supply chain with one single supplier and one single retailer, our results could be extended to the more general scenario where the supply chain has multiple periods and multiple members. Another possible extension of this study is to investigate the asymmetric information of the supplier's quantity cost quantity and the retailer's demand disruption.

\section{Conflict of Interests}

The authors declare that there is no conflict of interests regarding the publication of this paper.

\section{Acknowledgments}

This research was supported in part by project supported by the Humanities and Social Sciences Project of the Education Ministry (no. 14YJC630187) and the National HigherEducation Institution General Research and Development Project of North China Electric Power University (no. 2014QN43).

\section{References}

[1] C. B. Pickett, Strategies for Maximizing Supply Chain Resilience: Learning From the Past to Prepare for the Future, Massachusetts Institute of Technology, 2003.

[2] L. Qi, "A continuous-review inventory model with random disruptions at the primary supplier," European Journal of Operational Research, vol. 225, no. 1, pp. 59-74, 2013.
[3] B. Sarkar, S. Saren, and L. E. Cárdenas-Barrón, "An inventory model with trade-credit policy and variable deterioration for fixed lifetime products," Annals of Operations Research, vol. 229, pp. 677-702, 2015.

[4] A. H. L. Lau, H.-S. Lau, and Y.-W. Zhou, "Considering asymmetrical manufacturing cost information in a two-echelon system that uses price-only contracts," IIE Transactions, vol. 38, no. 3, pp. 253-271, 2006.

[5] V. Babich, A. N. Burnetas, and P. H. Ritchken, "Competition and diversification effects in supply chains with supplier default risk," Manufacturing \& Service Operations Management, vol. 9, no. 2, pp. 123-146, 2007.

[6] B. Sarkar, S. S. Sana, and K. Chaudhuri, "Optimal reliability, production lotsize and safety stock: an economic manufacturing quantity model," International Journal of Management Science and Engineering Management, vol. 5, no. 3, pp. 192-202, 2010.

[7] C. J. Corbett, "Stochastic inventory systems in a supply chain with asymmetric information: cycle stocks, safety stocks, and consignment stock," Operations Research, vol. 49, no. 4, pp. 487500, 2001.

[8] A. Y. Ha, "Supplier-buyer contracting: asymmetric cost information and cutoff level policy for buyer participation," Naval Research Logistics, vol. 48, no. 1, pp. 41-64, 2001.

[9] E. Sucky, "A bargaining model with asymmetric information for a single supplier-single buyer problem," European Journal of Operational Research, vol. 171, no. 2, pp. 516-535, 2006.

[10] M. Sarkar and B. Sarkar, "An economic manufacturing quantity model with probabilistic deterioration in a production system," Economic Modelling, vol. 31, no. 1, pp. 245-252, 2013.

[11] J. Li, X. Liu, J. Wu, and F. Yang, "Coordination of supply chain with a dominant retailer under demand disruptions," Mathematical Problems in Engineering, vol. 2014, Article ID 854681, 10 pages, 2014.

[12] L. Chen, Y. E. Liu, and S. S. Yang, "Robust supply chain strategies for recovering from unanticipated disasters," Transportation Research Part E: Logistics and Transportation Review, vol. 77, pp. 198-214, 2015.

[13] B. Sarkar, S. S. Sana, and K. Chaudhuri, "An economic production quantity model with stochastic demand in an imperfect production system," International Journal of Services and Operations Management, vol. 9, no. 3, pp. 259-283, 2011.

[14] A. H.-L. Lau and H.-S. Lau, "Some two-echelon style-goods inventory models with asymmetric market information," European Journal of Operational Research, vol. 134, no. 1, pp. 29-42, 2001.

[15] A. M. Ross, Y. Rong, and L. V. Snyder, "Supply disruptions with time-dependent parameters," Computers and Operations Research, vol. 35, no. 11, pp. 3504-3529, 2008.

[16] H. J. Weiss and E. C. Rosenthal, "Optimal ordering policies when anticipating a disruption in supply or demand," European Journal of Operational Research, vol. 59, no. 3, pp. 370-382, 1992.

[17] T. Xiao and G. Yu, "Supply chain disruption management and evolutionarily stable strategies of retailers in the quantitysetting duopoly situation with homogeneous goods," European Journal of Operational Research, vol. 173, no. 2, pp. 648-668, 2006.

[18] D. Xie and H. Chen, "Coordinating dual-channel supply chain under price mechanism with production cost disruption," Management Science and Engineering, vol. 9, no. 2, 2015. 
[19] B. Sarkar, K. Chaudhuri, and S. S. Sana, "A stock-dependent inventory model in an imperfect production process," International Journal of Procurement Management, vol. 3, no. 4, pp. 361378, 2010.

[20] X. U. Xiaoyan and W. U. Sanping, "Coordinating two_echelon supply chain with asymmetric information of manufacturing cost," Journal of Systems Engineering, vol. 24, pp. 18-24, 2009.

[21] Y. Shen and S. P. Willems, "Coordinating a channel with asymmetric cost information and the manufacturer's optimality," International Journal of Production Economics, vol. 135, no. 1, pp. 125-135, 2012.

[22] X. Qi, J. F. Bard, and G. Yu, "Supply chain coordination with demand disruptions," Omega, vol. 32, no. 4, pp. 301-312, 2004.

[23] T. J. Xiao, X. Qi, and G. Yu, "Coordination of supply chain after demand disruptions when retailers compete," International Journal of Production Economics, vol. 109, no. 1-2, pp. 162-179, 2007.

[24] G. P. Cachon and M. A. Lariviere, "Capacity choice and allocation: strategic behavior and supply chain performance," Management Science, vol. 45, no. 8, pp. 1091-1108, 1999.

[25] Y. Wang, W. Gilland, and B. Tomlin, "Mitigating supply risk: dual sourcing or process improvement?" Manufacturing and Service Operations Management, vol. 12, no. 3, pp. 489-510, 2010.

[26] M. Parlar and D. Perry, "Inventory models of future supply uncertainty with single and multiple suppliers," Naval Research Logistics, vol. 43, no. 2, pp. 191-210, 1996.

[27] M. Parlar and D. Berkin, "Future supply uncertainty in EOQ models," Naval Research Logistics, vol. 38, no. 1, pp. 107-121, 1991.

[28] D. Heimann and F. Waage, "A closed-form approximation solution for an inventory model with supply disruptions and non-ZIO reorder policy," Journal on Systemics, Cybernetics and Informatics, vol. 5, no. 4, pp. 1-12, 2007.

[29] C. J. Corbett, D. Zhou, and C. S. Tang, "Designing supply contracts: contract type and information asymmetry," Management Science, vol. 50, no. 4, pp. 550-559, 2004.

[30] X. Yao, X. Tavg, and J. Pan, "Buy-back contract of supply chain based on double auction mechanism," Chinese Journal of Management, vol. 6, no. 11, pp. 1444-1448, 2009.

[31] Q.-H. Zhang and J.-W. Luo, "Coordination of supply chain with trade credit under bilateral information asymmetry," System Engineering Theory and Practice, vol. 29, no. 9, pp. 32-40, 2009.

[32] X.-H. Wang, X.-Y. Wang, and Y.-S. Su, "The coordination mechanism of supply chain with bilateral asymmetric costs information," Journal of Industrial Engineering and Engineering Management, vol. 27, no. 4, pp. 196-204, 2013.

[33] X.-H. Wang, X.-Y. Wang, and Y.-S. Su, "Coordination and efficiency analysis of supply chain with bilateral asymmetric information," Computer Integrated Manufacturing Systems, vol. 18, no. 6, pp. 1271-1280, 2012.

[34] G. P. Cachon, "Supply chain coordination with contract," in Handbooks in Operations Research and Management Science: Supply Chain Management, pp. 233-236, North Holland, Amsterdam, The Netherlands, 2004.

[35] S.-K. Lim, J.-G. Kim, and Y.-H. Shin, "Optimal three-level presort loading of commercial bulk mail in the postal service industry," Journal of the Operation Research Society, vol. 66, pp. 1007-1022, 2015.

[36] P. Chone and L. Linnemer, "Nonlinear pricing and exclusion: I. Buyer opportunism," Rand Journal of Economics, vol. 46, pp. 217-240, 2015.
[37] Z. Kevin Weng, "Modeling quantity discounts under general price-sensitive demand functions: optimal policies and relationships," European Journal of Operational Research, vol. 86, no. 2, pp. 300-314, 1995.

[38] B. C. Giri, A. Chakraborty, and T. Maiti, "Quality and pricing decisions in a two-echelon supply chain under multimanufacturer competition," International Journal of Advanced Manufacturing Technology, vol. 78, pp. 1927-1941, 2015.

[39] H. Yu, A. Z. Zeng, and L. Zhao, "Single or dual sourcing: decision-making in the presence of supply chain disruption risks," Omega, vol. 37, no. 4, pp. 788-800, 2009. 


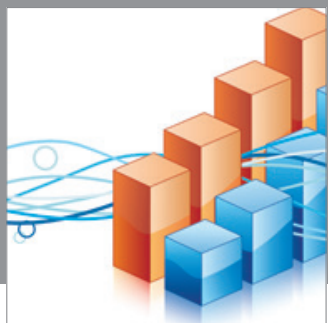

Advances in

Operations Research

mansans

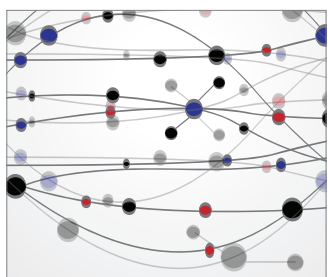

The Scientific World Journal
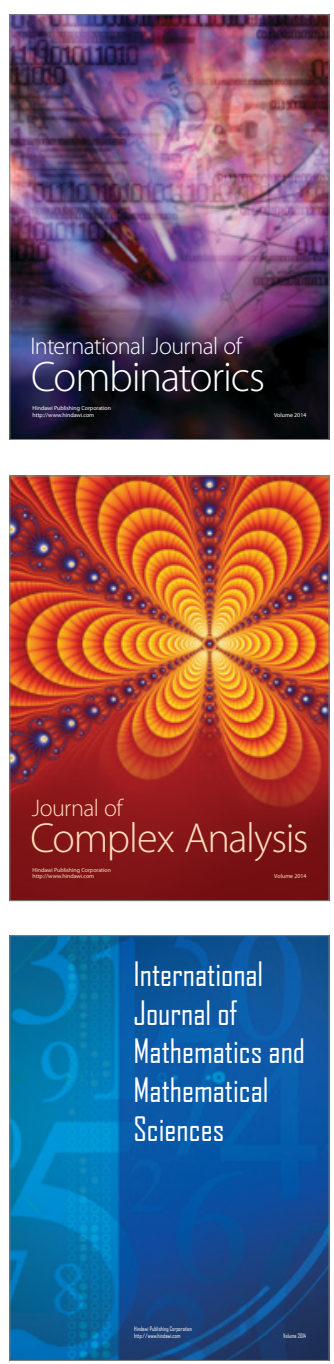
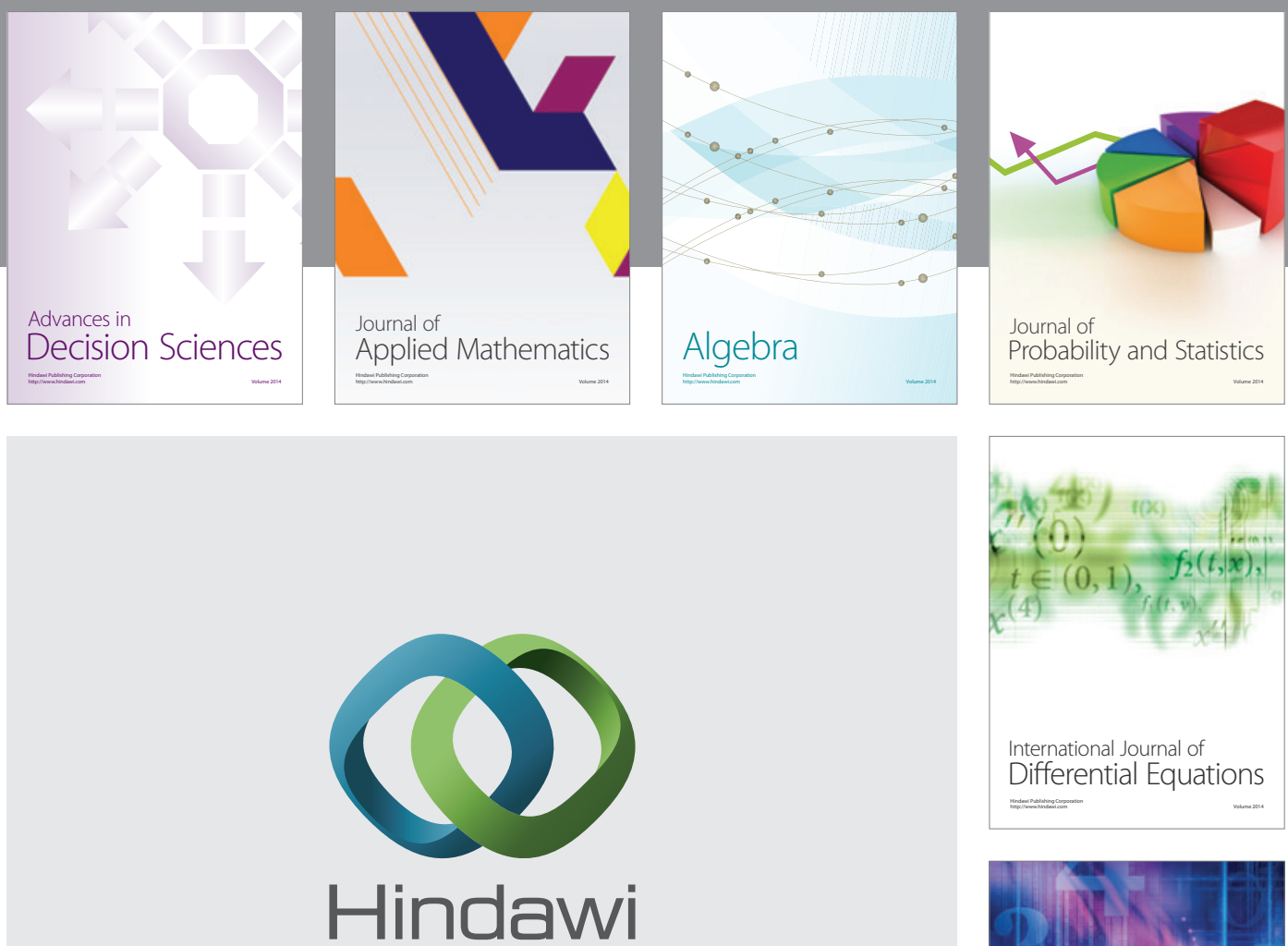

Submit your manuscripts at http://www.hindawi.com
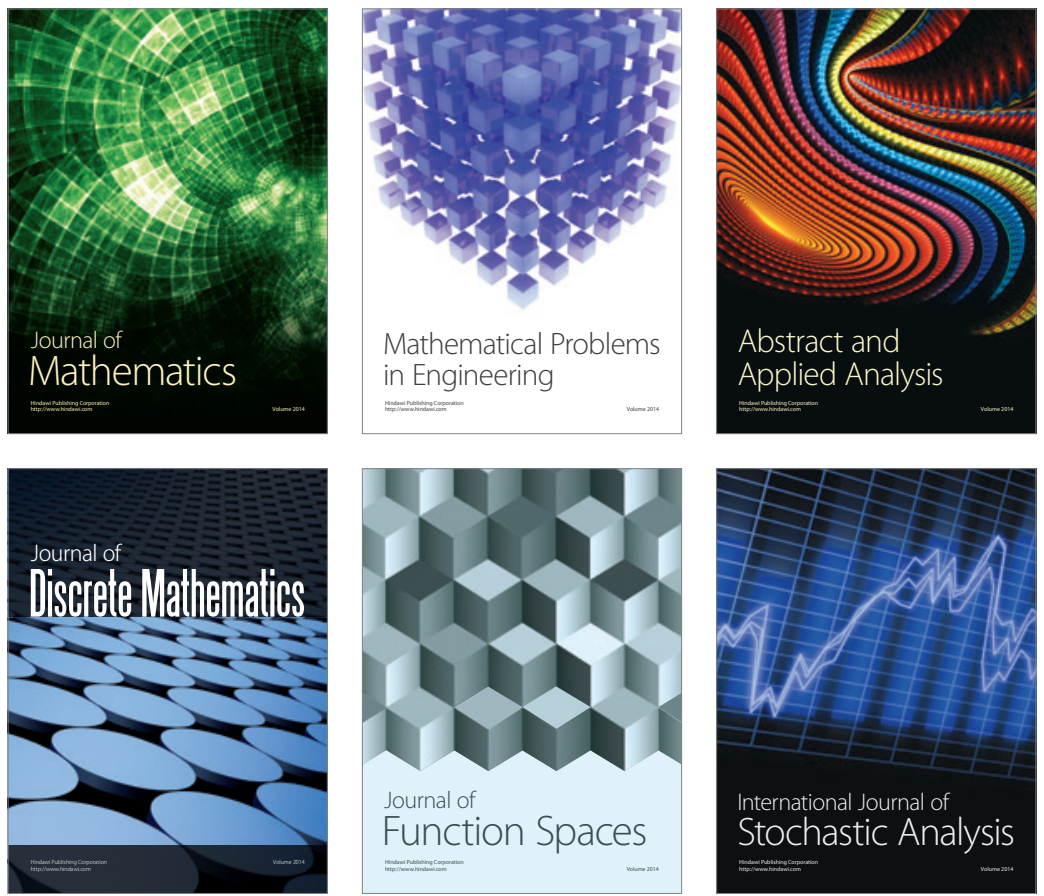

Journal of

Function Spaces

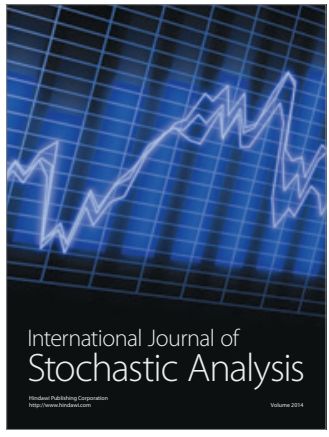

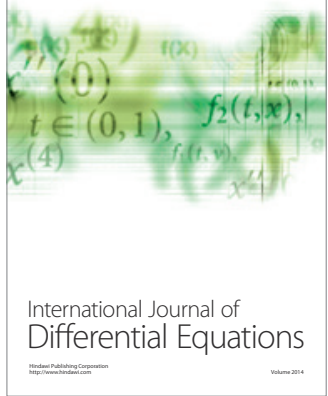
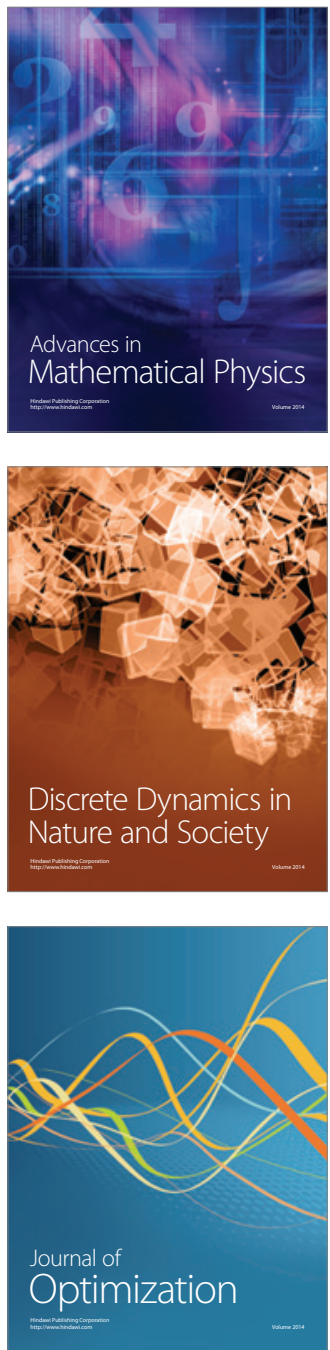